\title{
Nasal and perirectal colonization of vancomycin sensitive and resistant enterococci in patients of paediatrics ICU (PICU) of tertiary health care facilities
}

Muhammad Arfat Yameen ${ }^{1,2^{*}}$, Saira Iram², Abdul Mannan', Shujaat Ali Khan ${ }^{1}$ and Naeem Akhtar ${ }^{3,4}$

\begin{abstract}
Background: Enterococci normally inhabit the intestinal tract of humans and are also a potential pathogen in causing nosocomial infections. The increase in antibiotic resistance and transfer of antibiotic resistance gene to Staphylococcus aureus (S. aureus) due to co-colonization has increased its importance in research. The aim of the study was to evaluate local epidemiology of nasal and rectal colonization with Enterococcus faecalis (E. faecalis) and Enterococcus faecium (E. faecium) in patients of Paediatrics Intensive Care Unit (PICU) and correlation with clinical and socioeconomic factors.

Methods: The nasal and perirectal swab samples were collected from 110 patients admitted in PICUs of three tertiary care hospitals of Rawalpindi Medical College, Pakistan. The identification of enterococci was done by biochemical tests and by PCR for ddl, vanA and vanB genes. Antibiotic susceptibility testing was performed by disc diffusion and MICs were determined for vancomycin, tetracycline, ciprofloxacin and oxacillin only.

Results: Out of 220 nasal and perirectal samples, 09 vancomycin-resistant enterococci (VRE) and 76 vancomycinsusceptible enterococci (VSE), consisting of $40 \mathrm{E}$. faecalis and $45 \mathrm{E}$. faecium were isolated. PCR successfully identified both species with $d d l$ primers and VRE with vanA primer. With disc diffusion method, all isolates were resistant to most of the antibiotics tested except linezolid, quinupristin/dalfopristin, teicoplanin and vancomycin. VRE showed resistance to teicoplanin and vancomycin both and none was resistant to linezolid and quinupristin/dalfopristin. Generally, E. faecium isolates were more resistant than E. faecalis. MICs of vancomycin for nasal and perirectal VRE were $512 \mathrm{mg} / \mathrm{L}$ and 64 to $512 \mathrm{mg} / \mathrm{L}$ respectively. VRE were more in patients with prolonged hospitalization, from urban localities and those having pneumonia.

Conclusion: Present study reveals high colonization and antibiotic resistance in enterococcal isolates from nasal and perirectal area. Nasal colonization by enterococci in PICU is more alarming as VRE may cause infection and can transfer this resistance gene to other microorganisms like $S$. aureus.
\end{abstract}

Keywords: Enterococci colonization, Antimicrobial susceptibility, Vancomycin resistant enterococci

\footnotetext{
* Correspondence: arfatyameen@yahoo.com

'Department of Pharmaceutical Sciences, COMSATS Institute of Information

Technology, Abbottabad 22060, Pakistan

${ }^{2}$ Microbiology Research Laboratory, Department of Microbiology,

Quaid-I-Azam University, Islamabad 45320, Pakistan

Full list of author information is available at the end of the article
} 


\section{Background}

Enterococci normally inhabit the intestinal tract of humans and animals and may colonize the human oral cavity, vagina, hepatobiliary tract and skin of healthy individuals [1]. Two species, E. faecalis and E. faecium, have been more frequently isolated from clinical samples than other species of enterococci, accounting for 80 to $90 \%$ and 5 to $10 \%$, respectively [2].

As compared to other Gram-positive organisms, enterococci have relatively low virulence but, in recent years they have emerged as the nosocomial pathogens of the 1990s [3-6]. Several factors, including ubiquitous distribution as intestinal flora and the widespread use of broad-spectrum antibiotics and invasive devices have contributed to the emergence of enterococci as important pathogens [7] and perhaps most important is their extensive resistance to a wide range of antimicrobial agents. These properties allow this organism to survive and multiply with a selective advantage over other fecal flora in a hospital environment where antimicrobial agents are heavily used. The aim of the study was to evaluate local epidemiology of nasal and rectal colonization with $E$. faecalis and E. faecium in PICUs patients and correlation with clinical and socioeconomic factors.

S. aureus persistently or intermittently can colonize the nasal cavity and perirectal area of healthy humans and transfer of vancomycin-resistant gene due to cocolonization with enterococci has been reported in some previous studies, so nasal samples were also collected with the hypothesis that enterococci (E. faecalis and $E$. faecium) can co-exist with $S$. aureus and may transfer resistance gene [8-11].

The study also included risk factors like age of the patient, reason for admission, stay of patient in the hospital at the time of sampling, residential (rural, urban) and socioeconomic status (high, middle, low) of the patients.

\section{Methods}

The prospective microbiological surveillance study was carried out at Microbiology Laboratory, Holy Family Hospital, Rawalpindi, Pakistan and Microbiology Research Laboratory, Quaid-I-Azam University, Islamabad, Pakistan during the period from March to September 2010. After ethical approval of study, granted by Ethical Committee of RMC and Allied Hospitals, Rawalpindi, Pakistan (No. EC/1721-22/RMC/dated: 03/03/2010), written consents were taken from the parents and guardians of the children before sampling. Samples of the anterior nares and perirectal area were obtained from every patient admitted in PICUs of Allied Hospitals of Rawalpindi Medical College, Rawalpindi, Pakistan, either newly admitted or transferred from other units of the same or different hospitals. Patients with duplicate admissions during the study period were excluded.
Samples were processed within two hours of collection. The swabs were inoculated onto Bile Aesculin Agar (BAA) (Oxoid, UK) plates and were incubated at $45^{\circ} \mathrm{C}$ for 24 to 72 hours. Characteristic pinpoint colonies and colonies with black zone around were subcultured on Mueller Hinton Agar (MHA) with $6 \% \mathrm{NaCl}$ (Oxoid, UK) at $45^{\circ} \mathrm{C}$ for confirmation. Further identification of these isolates was done by pink or red colonies on KF Streptococci Agar (KFSA) (Oxoid, UK), negative catalase and coagulase tests and gamma-hemolysis on Sheep Blood Agar (SBA) (Oxoid, UK) after overnight growth at $37^{\circ} \mathrm{C}$. All confirmed enterococci isolates were preserved in $16 \% \mathrm{v} / \mathrm{v}$ glycerol broth and in Microbank tubes (Pro-Lab Diagnostics, US) at $-70^{\circ} \mathrm{C}$.

\section{Molecular identification}

The species identification of enterococci (E. faecalis and E. faecium) was done using PCR by targeting $\mathrm{ddl}_{E \text {. faecalis }}$ and $\mathrm{ddl}{ }_{\text {E. faecium }}$ genes. The vancomycin-resistant gene was identified with $v a n A$ and $v a n B$ primers. All the primer sequences used have been used in previous studies [12] and were obtained from Sigma Genoßys (Sigma Aldrich, USA), Alpha DNA (Alpha DNA, Germany) and e-Oligo (Gene Link, USA) (Table 1).

DNA was extracted with Wizard ${ }^{\circledR}$ Genomic DNA purification kit (Promega Corporation, USA) according to manufacturer's instructions. DNA was also extracted manually with Triton X lysis buffer by the method used in the previous study for DNA extraction from bacterial colonies [13]. The isolated DNA was stored at 2 to $8^{\circ} \mathrm{C}$.

Amplification was carried out in Biometra T1 Thermocycler (Biometra, Germany) with initial denaturation at $95^{\circ} \mathrm{C}$ for $4 \mathrm{~min}$, then 30 cycles of denaturation at $95^{\circ} \mathrm{C}$ for $30 \mathrm{sec}$., annealing at $52^{\circ} \mathrm{C}$ for $1 \mathrm{~min}$ and extension at $72^{\circ} \mathrm{C}$ for 2 min followed by final extension at $72^{\circ} \mathrm{C}$ for $7 \mathrm{~min}$. The final PCR product was held at $4^{\circ} \mathrm{C}$ until removed.

The PCR product was analysed on $1 \%$ agarose gel. DNA ladder (O'Gene Ruler) of $100 \mathrm{bp}$ and $1 \mathrm{~kb}$ was used to compare the size of PCR amplified fragments. Electrophoresis was done at $100 \mathrm{~V}$ for one hour and gel was viewed under Molecular Imager Gel Doc XR + System, Bio-Rad Laboratories, US.

\section{Antimicrobial susceptibility testing}

Antimicrobial susceptibility testing was performed by Kirby-Bauer modified disc diffusion method [14] according to CLSI guidelines [15] using MHA plates. The antibiotic discs used were ampicillin, amoxicillin/ clavulanic acid, methicillin, oxacillin, penicillin G, cephalexin, cefoxitin, cephalothin, cephradine, ciprofloxacin, levofloxacin, erythromycin, tetracycline, gentamicin, imipenem, linezolid, quinupristin/dalfopristin, teicoplanin and vancomycin. Minimum inhibitory 
Table 1 Oligonucleotides primers used for enterococci

\begin{tabular}{|c|c|c|c|c|}
\hline Primer designation & Sequences $(5 \rightarrow 3)$ & Product size (bp) & Company & Reference \\
\hline \multicolumn{5}{|l|}{ E. faecium } \\
\hline$d d l_{\text {E. faecium }(1)}$ & TTGAGGCAGACCAGATTGACG & 658 & Alpha DNA/Sigma & Kariyama et al., 2000 \\
\hline$\left.d d\right|_{\text {E. faecium (2) }}$ & TATGACAGCGACTCCGATTCC & & & \\
\hline \multicolumn{5}{|l|}{ E. faecalis } \\
\hline$d d l_{\text {E.faecalis(1) }}$ & ATCAAGTACAGTTAGTCT & 941 & Alpha DNA/Sigma & Kariyama et al., 2000 \\
\hline$d d l_{\text {E. faecalis(2) }}$ & ACGATTCAAAGCTAACTG & & & \\
\hline $\operatorname{van} A(1)$ & GGGAAAACGACAATTGC & 732 & Alpha DNA/e-Oligo & Kariyama et al., 2000 \\
\hline $\operatorname{van} A(2)$ & GTACAATGCGGCCGTTA & & & \\
\hline $\operatorname{van} B(1)$ & GTGCTGCGAGATACCACAGA & 635 & Alpha DNA/e-Oligo & Kariyama et al., 2000 \\
\hline $\operatorname{vanB}(2)$ & CGAACACCATGCAACATTTC & & & \\
\hline
\end{tabular}

concentrations (MICs) for ciprofloxacin, oxacillin, tetracycline and vancomycin were determined with agar dilution method according to British Society for Antimicrobial Chemotherapy Guidelines [16]. Standard antibiotic powders were obtained from MP Biomedicals UK. Stock solutions were prepared according to manufacturer's instructions. Following breakpoint concentrations of these antibiotics were used: tetracycline $1 \mathrm{mg} / \mathrm{L}$, oxacillin $2 \mathrm{mg} / \mathrm{L}$, ciprofloxacin $4 \mathrm{mg} / \mathrm{L}$ and vancomycin $8 \mathrm{mg} / \mathrm{L}$.

\section{Patient's clinical data}

Patient's data, including age ( $<12$ years), gender, residential and socioeconomic status, clinical diagnosis, history of vancomycin intake, surgical interventions, invasive procedure and devices, current medication profile was collected from the hospital record.

The Statistical Package for Social Sciences (SPSS) version 13.0 was used for statistical analysis by average, \pm standard deviation, chi-square test (Cross tabulation) and $t$-test. The p-value $\leq 0.05$ was considered as "statistical significant."

\section{Results}

In nasal samples, there were 29/110 (26.4\%) enterococci, including 03/29 (10.3\%) VRE (02 E. faecalis and 01 E. faecium) and 26/29 (89.7\%) VSE (09 E. faecalis and 17 E. faecium). The remaining 81/110 (73.6\%) nasal samples gave no enterococcal growth (Table 2).

In perirectal samples, 56/110 (50.9\%) enterococci were isolated with $06 / 56$ (10.7\%) VRE isolates (03 each of $E$. faecalis and E. faecium) and 50/56 (89.3\%) VSE isolates (26 E. faecalis and 24 E. faecium). Fifty four perirectal samples gave no growth of enterococci (Table 2). Sixteen patients had enterococci in both their nasal and perirectal samples. Statistically significant association was found in nasal and perirectal enterococcal isolation (Chi-square test: 75.314, $\mathrm{P}<0.001$ ).

PCR successfully identified 85/220 (38.6\%) enterococci in both nasal and perirectal samples with the help of $d d l_{E \text {. faecalis and }} d d l_{\text {E. faecium primers. In these, } 40 / 85}$ (47.1\%) were E. faecalis and $45 / 85$ (52.9\%) were $E$. faecium. Similarly, all 09/85 (10.6\%) VRE were identified with $v a n A$ primer. No enterococcal isolates gave amplification with $v a n B$ primer.

\section{Antimicrobial susceptibility testing}

With disc diffusion method, all nasal and perirectal isolates were 66 to $100 \%$ resistant to cephalexin, cefoxitin, cephalothin, cephradine, ciprofloxacin, erythromycin, gentamicin, methicillin and oxacillin. Whereas nasal isolates were 36 to $55 \%$ resistant to penicillin G, ampicillin, amoxicillin/clavulanic acid, imipenem, levofloxacin and tetracycline, while perirectal isolates showed variable resistance to these antibiotics. Both nasal and perirectal isolates were 05 to $18 \%$ resistant to teicoplanin and vancomycin and were susceptible to linezolid and quinupristin/dalfopristin (Table 3). Perirectal E. faecium isolates showed higher resistance than $E$. faecalis in disc diffusion test.

Among nasal isolates, 03/29 (10.3\%) were VRE (break point (bp) $\geq 08 \mathrm{mg} / \mathrm{L}$ ) and $26 / 29$ (89.7\%) were VSE (bp $<08 \mathrm{mg} / \mathrm{L})$. One isolate of $E$. faecalis and one isolate of

Table 2 Frequency of VRE and VSE in paediatrics intensive care units

\begin{tabular}{|c|c|c|c|c|c|}
\hline & $\begin{array}{l}\text { VRE faecium } \\
\text { n (\%) }\end{array}$ & $\begin{array}{l}\text { VRE faecalis } \\
\text { n (\%) }\end{array}$ & $\begin{array}{l}\text { VSE faecium } \\
\text { n (\%) }\end{array}$ & $\begin{array}{l}\text { VSE faecalis } \\
\text { n (\%) }\end{array}$ & $\begin{array}{l}\text { No Enterococci } \\
\text { n (\%) }\end{array}$ \\
\hline Nasal $(n=110)$ & $1(0.9)$ & $2(1.8)$ & $17(15.5)$ & $9(8.2)$ & 81 (73.6) \\
\hline Perirectal $(n=110)$ & $3(2.7)$ & $32.7)$ & $24(21.8)$ & $26(23.6)$ & $54(49.1)$ \\
\hline Total & 4 & 5 & 41 & 35 & 135 \\
\hline
\end{tabular}


Table 3 Antibiotics resistant pattern of nasal and perirectal enterococci by disc diffusion method

\begin{tabular}{|c|c|c|c|c|}
\hline \multirow[t]{3}{*}{ Antibiotic discs (abbreviations) } & \multicolumn{2}{|c|}{ Nasal isolates } & \multicolumn{2}{|c|}{ Perirectal isolates } \\
\hline & \multicolumn{2}{|c|}{$(n=29)$} & \multicolumn{2}{|c|}{$(n=56)$} \\
\hline & E. faecalis $(n=11)$ & E. faecium $(n=18)$ & E. faecalis $(n=29)$ & E. faecium $(n=27)$ \\
\hline \multicolumn{5}{|l|}{ \% Resistance } \\
\hline Co-amoxyclav $\mathbf{3 0} \boldsymbol{\mu g}$ (AMC 30$)$ & 36.4 & 50 & 13.8 & 70.4 \\
\hline Ampicillin $\mathbf{2 5} \boldsymbol{\mu} \mathbf{g}$ (AMP25) & 36.4 & 50 & 13.8 & 70.4 \\
\hline Cefoxitin $\mathbf{3 0} \boldsymbol{\mu g}$ (FOX30) & 100 & 100 & 93.1 & 100 \\
\hline Cephalexin $\mathbf{3 0} \boldsymbol{\mu g}(\mathrm{CL} 30)$ & 90.9 & 77.8 & 100 & 96.3 \\
\hline Cephalothin $\mathbf{3 0} \boldsymbol{\mu g}$ (KF30) & 81.8 & 66.7 & 75.9 & 96.3 \\
\hline Cephradine $\mathbf{3 0} \boldsymbol{\mu} \mathbf{g}$ (CE30) & 81.8 & 94.4 & 100 & 100 \\
\hline Ciprofloxacin $\mathbf{5} \boldsymbol{\mu g}$ (CIP5) & 81.8 & 66.7 & 69 & 96.3 \\
\hline Erythromycin $\mathbf{1 5} \boldsymbol{\mu g}$ (E15) & 90.9 & 88.9 & 79.3 & 96.3 \\
\hline Gentamicin $\mathbf{3 0} \boldsymbol{\mu g}$ (CN30) & 72.7 & 83.3 & 79.3 & 92.6 \\
\hline Imipenem $10 \boldsymbol{\mu g}(\mathrm{IPM10})$ & 45.5 & 55.6 & 24.1 & 85.2 \\
\hline Levofloxacin $\mathbf{5} \boldsymbol{\mu g}$ (LEV5) & 45.5 & 50 & 62.1 & 92.6 \\
\hline Linezolid $\mathbf{3 0} \boldsymbol{\mu g}$ (LZD30) & 0 & 0 & 0 & 0 \\
\hline Methicillin $10 \boldsymbol{\mu g}$ (MET10) & 100 & 100 & 96.6 & 100 \\
\hline Oxacillin $\mathbf{1} \boldsymbol{\mu} \mathbf{g}(\mathrm{O} \times 1)$ & 100 & 100 & 100 & 100 \\
\hline Penicillin G 10 IU (P10) & 36.4 & 55.6 & 31 & 85.2 \\
\hline Quinupristin/Dalfopristin $\mathbf{1 5} \boldsymbol{\mu g}$ (QD15) & 0 & 0 & 0 & 0 \\
\hline Teicoplanin $\mathbf{3 0} \boldsymbol{\mu} \mathbf{g}(\mathrm{TEC} 30)$ & 18.2 & 5.6 & 10.3 & 11.1 \\
\hline Tetracycline $\mathbf{3 0} \boldsymbol{\mu g}$ (TE30) & 36.4 & 50 & 75.9 & 70.4 \\
\hline Vancomycin $\mathbf{3 0} \boldsymbol{\mu} \mathbf{g}$ (VA30) & 18.2 & 5.6 & 10.3 & 11.1 \\
\hline
\end{tabular}

E. faecium had MIC $512 \mathrm{mg} / \mathrm{L}(t$-test, $\mathrm{P}>0.05)$. MICs of tetracycline ranged from 02 to $256 \mathrm{mg} / \mathrm{L}(t$-test, $\mathrm{P}<$ $0.05)$ for both nasal E. faecalis and E. faecium and all were tetracycline resistant ( $\mathrm{bp} \geq 01 \mathrm{mg} / \mathrm{L}$ ). The MICs of ciprofloxacin for nasal E. faecalis and E. faecium ranged from 01 to $256 \mathrm{mg} / \mathrm{L}$ and 02 to $512 \mathrm{mg} / \mathrm{L}$ respectively. Only 04/29 (13.8\%) isolates (02 from each species) were inhibited at concentration of $<04 \mathrm{mg} / \mathrm{L}$ and were considered susceptible, rests of 25/29 (86.2\%) were resistant. Ttest statistic gave $\mathrm{P}>0.05$ for $E$. faecalis and $\mathrm{P}<0.05 E$. faecium. In case of oxacillin, MICs ranged from 08 to $512 \mathrm{mg} / \mathrm{L}(t$-test, $\mathrm{P}<0.05)$ and from 04 to $512 \mathrm{mg} / \mathrm{L}(t$ test, $\mathrm{P}<0.05)$ for $E$. faecalis and $E$. faecium respectively, indicating that all isolates are resistant (Table 4).

In perirectal isolates, 06/56 (10.7\%), 03 E. faecalis and 03 E. faecium were VRE with vancomycin MICs from 64 to $512 \mathrm{mg} / \mathrm{L}$, while remaining 50/56 (89.3\%), $26 E$. faecalis and 24 E. faecium were VSE ( $t$-test, $\mathrm{P}>0.05$ ). There is not much difference in MICs of perirectal isolates than those of nasal isolates. For tetracycline, 08/56 (14.3\%) isolates, (05/29 E. faecalis and 03/27 E. faecium) were inhibited at $0.5 \mathrm{mg} / \mathrm{L}$ ( $\mathrm{bp}>01 \mathrm{mg} / \mathrm{L}$ ) and were susceptible, while remaining of the isolates were resistant showing MICs in range from 64 to $256 \mathrm{mg} / \mathrm{L}$ and 01 to $256 \mathrm{mg} / \mathrm{L}$ for both of species respectively $(t$-test, $\mathrm{P}<0.05)$.
For ciprofloxacin all $E$. faecalis and $E$. faecium were resistant with MICs from 04 to $512 \mathrm{mg} / \mathrm{L}(t$-test, $\mathrm{P}<0.05)$. The oxacillin MICs ranged from 8 to $512 \mathrm{mg} / \mathrm{L}$ for both isolates and were resistant $(t$-test, $\mathrm{P}<0.05)$ (Table 5).

\section{Patient's clinical data}

In this study, the average patient stay was 5.42 (SD \pm 5.79) days in PICU at the time of sampling. Statistically, no significant association was found in rate of enterococcal isolation with duration of stay of patients in PICU (Chi-square test: nasal: 20.505 \& perirectal: 19.481, P > 0.05). However, the isolation of VRE both form nasal and perirectal area was more form patients who have longer hospital stay. There were 06/09 VRE isolates from patients who stayed more than two days in the unit (Table 6).

Patients with age group $<1$ year were more colonized with both types of enterococci than other age groups. These were $8 / 26(30.8 \%)$ E. faecalis and 12/26 (34\%) E. faecium from nasal (Chi-square test: 14.733, P > 0.05) and $17 / 50(30.8 \%)$ E. faecalis and $14 / 50$ (34\%) E. faecium from perirectal samples (Chi-square test: 5.407, $\mathrm{P}>0.05)$. The VRE isolation was almost equal in all the three age groups with no significant association with enterococci isolation. 
Table 4 MICs of nasal enterococci

\begin{tabular}{|c|c|c|c|c|c|c|c|c|}
\hline \multirow[b]{3}{*}{ Antibiotic dilutions } & \multicolumn{8}{|c|}{ Nasal isolates $(n=29)$} \\
\hline & \multicolumn{4}{|c|}{ E. faecalis $(n=11)$} & \multicolumn{4}{|c|}{ E. faecium $(n=18)$} \\
\hline & TET (\%) & CIP (\%) & OXA(\%) & VAN (\%) & TET (\%) & CIP (\%) & OXA (\%) & VAN (\%) \\
\hline 0.5 & -——- & -——— & -——- & -——- & -——— & -——- & -——— & -——- \\
\hline 1 & + & $1(9.1)$ & & $5(45.5)$ & + & -—— & -——_ & $11(61.1)$ \\
\hline 2 & $2(18.2)$ & $1(9.1)$ & ${ }^{+}$ & $3(27.3)$ & $2(11.1)$ & $2(11.1)$ & ${ }^{+}$ & $6(33.3)$ \\
\hline 4 & $2(18.2)$ & + & - - - & $1(9.1)$ & $1(5.6)$ & $t^{+2(11.1)}$ & $1(5.6)$ & - - \\
\hline 8 & $1(9.1)$ & $3(27.3)$ & $1(9.1)$ & + & $3(16.7)$ & $2(11.1)$ & $1(5.6)$ & + \\
\hline 16 & -二 - & $1(9.1)$ & $1(9.1)$ & -——- & $1(5.6)$ & - - - & $1(5.6)$ & -— \\
\hline 32 & ——— & $2(18.2)$ & $2(18.2)$ & -—— & - - & $3(16.7)$ & $1(5.6)$ & -—— \\
\hline 64 & -——- & $1(9.1)$ & $2(18.2)$ & - - - & $1(5.6)$ & -——- & $1(5.6)$ & - - \\
\hline 128 & $3(27.3)$ & $1(9.1)$ & $2(18.2)$ & -— & $6(33.3)$ & $3(16.7)$ & $3(16.7)$ & - \\
\hline 256 & $3(27.3)$ & $1(9.1)$ & $1(9.1)$ & - & $4(22.2)$ & $4(22.2)$ & $6(33.3)$ & - \\
\hline 512 & -—— & -二- & $2(18.2)$ & $2(18.2)$ & -二- & $2(11.1)$ & $4(22.2)$ & $1(5.6)$ \\
\hline \multirow[t]{2}{*}{$t$-test } & $P<0.05$ & $P=0.076$ & $P<0.05$ & $P=0.195$ & $P<0.05$ & $P<0.05$ & $P<0.05$ & $P=454$ \\
\hline & $t=3.182$ & $\mathrm{t}=1.981$ & $t=2.772$ & $t=1.389$ & $t=4.488$ & $t=3.499$ & $t=5.239$ & $t=0.766$ \\
\hline
\end{tabular}

${ }^{\dagger}$ Breakpoint concentration, TET: Tetracycline, CIP: Ciprofloxacin, OXA: Oxacillin, VAN: Vancomycin. 
Table 5 MICs of perirectal enterococci

\begin{tabular}{|c|c|c|c|c|c|c|c|c|}
\hline \multirow[b]{3}{*}{ Antibiotic dilutions } & \multicolumn{8}{|c|}{ Perirectal isolates $(n=56)$} \\
\hline & \multicolumn{4}{|c|}{ E. faecalis $(n=29)$} & \multicolumn{4}{|c|}{ E. faecium $(n=27)$} \\
\hline & TET (\%) & CIP (\%) & OXA(\%) & VAN (\%) & TET (\%) & CIP (\%) & OXA(\%) & VAN (\%) \\
\hline 0.5 & $5(17.2)$ & -——- & -——- & -—— & $3(11.1)$ & -—— & -二—- & -——- \\
\hline 1 & + & - - - & -——- & $12(41.4)$ & ${ }^{t_{1(3.7)}}$ & -—— & - - - & $12(44.4)$ \\
\hline 2 & - - & $1(3.4)$ & + & $12(41.4)$ & -——- & -——- & + & $10(37)$ \\
\hline 4 & 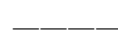 & ${ }^{\dagger} \underline{4(13.8)}$ & - _- & $2(6.9)$ & $5(18.5)$ & $\stackrel{+}{2} 2(7.4)^{2}$ & -——— & $2(7.4)$ \\
\hline 8 & 一- & $5(17.2)$ & $1(3.4)$ & + & -——- & $5(18.5)$ & $1(3.7)$ & + \\
\hline 16 & 一一 & $2(6.9)$ & $7(24.1)$ & -二 & $3(11.1)$ & $2(7.4)$ & $1(3.7)$ & - \\
\hline 32 & 一一 & $7(24.1)$ & $8(27.6)$ & -——— & $2(7.4)$ & $3(11.1)$ & $4(14.8)$ & -—- \\
\hline 64 & $2(6.9)$ & -—— & $2(6.9)$ & $1(3.4)$ & $2(7.4)$ & $4(14.8)$ & $2(7.4)$ & -—- \\
\hline 128 & $10(34.5)$ & $3(10.3)$ & $2(6.9)$ & -—— & $3(11.1)$ & $2(7.4)$ & $3(11.1)$ & -——- \\
\hline 256 & $12(41.4)$ & $5(17.9)$ & $3(10.3)$ & -—— & $8(29.6)$ & $5(18.5)$ & $3(11.1)$ & -—- \\
\hline 512 & -—— & $2(6.9)$ & $6(20.7)$ & $2(6.9)$ & -——- & $4(14.8)$ & $13(48.1)$ & $3(11.1)$ \\
\hline \multirow[t]{2}{*}{$t$-test } & $P<0.05$ & $P<0.05$ & $P<0.05$ & $P=0.214$ & $P<0.05$ & $P<0.05$ & $P<0.05$ & $P=0.121$ \\
\hline & $t=8.611$ & $t=3.666$ & $t=4.273$ & $\mathrm{t}=1.271$ & $t=4.659$ & $t=4.204$ & $t=7.070$ & $t=1.601$ \\
\hline
\end{tabular}


Table 6 Association of different risk factors with enterococci colonization

\begin{tabular}{|c|c|c|c|c|c|c|c|}
\hline \multirow[t]{2}{*}{ Factors } & \multirow{2}{*}{$\begin{array}{l}\text { No. of patients }(n=110) \\
\text { Number }(\%)\end{array}$} & \multicolumn{2}{|c|}{$\begin{array}{l}\text { VSE nasal enterococci } \\
\qquad(n=26)\end{array}$} & \multicolumn{2}{|c|}{$\begin{array}{c}\text { VSE perirectal } \\
\text { enterococci }(n=50) \\
\end{array}$} & \multirow{2}{*}{$\begin{array}{l}\text { VRE nasal }(\mathrm{n}=3) \\
\text { E. faecalis } \\
\text { E. faecium (\%) }\end{array}$} & \multirow{2}{*}{$\begin{array}{c}\text { VRE perirectal }(n=6) \\
\text { E. faecalis } \\
\text { E. faecium (\%) }\end{array}$} \\
\hline & & $\begin{array}{l}\text { E. faecalis } \\
(\%)\end{array}$ & $\begin{array}{l}\text { E. faecium } \\
(\%)\end{array}$ & $\begin{array}{c}E . \\
\text { faecalis } \\
(\%)\end{array}$ & $\begin{array}{c}E . \\
\text { faecium } \\
(\%)\end{array}$ & & \\
\hline \multicolumn{8}{|l|}{ Age of patients } \\
\hline$\cdot<1$ & $69(62.7)$ & $8(30.8)$ & $12(46.2)$ & $17(34)$ & $14(28)$ & $1(33.3)$ & $2(33.3)$ \\
\hline$\cdot 1$ to $<6$ & $29(26.4)$ & 0 & $5(19.2)$ & $7(14)$ & $7(14)$ & $1(33.3)$ & $3(50)$ \\
\hline$\cdot 6$ to $<12$ & $12(10.9)$ & $1(3.9)$ & 0 & $2(4)$ & $3(6)$ & $1(33.3)$ & $1(16.7)$ \\
\hline \multicolumn{8}{|l|}{ Reason for Admission } \\
\hline - Miscellaneous group & $26(23.6)$ & $2(7.7)$ & $3(11.5)$ & $7(14)$ & $9(18)$ & $1(33.3)$ & $1(16.7)$ \\
\hline - Aspiration Pneumonia & $1(0.9)$ & 0 & 0 & $1(2)$ & 0 & 0 & 0 \\
\hline - Meningitis & $11(10)$ & 0 & $1(3.9)$ & $3(6)$ & $1(2)$ & 0 & $2(33.3)$ \\
\hline - Pneumonia & $68(61.8)$ & $7(26.9)$ & $13(50)$ & $15(30)$ & $14(28)$ & $2(66.7)$ & $3(50)$ \\
\hline - Renal Failure & $2(1.8)$ & 0 & 0 & 0 & 0 & 0 & 0 \\
\hline - Tuberculosis & $2(1.8)$ & 0 & 0 & 0 & 0 & 0 & 0 \\
\hline \multicolumn{8}{|l|}{ Duration of stay } \\
\hline • 0 day & $13(11.8)$ & $3(11.5)$ & $3(11.5)$ & $6(12)$ & $2(4)$ & 0 & 0 \\
\hline - 1 day & $13(11.8)$ & 0 & $1(3.9)$ & $3(6)$ & $3(6)$ & 0 & $1(16.7)$ \\
\hline$\cdot 2$ days & $20(18.2)$ & $3(11.5)$ & $3(11.5)$ & $5(10)$ & $5(10)$ & $1(33.3)$ & $1(16.7)$ \\
\hline - 3 to 5 days & $24(21.8)$ & $1(3.9)$ & $3(11.5)$ & $5(10)$ & $4(8)$ & 0 & 0 \\
\hline - 6 to 10 days & $22(20)$ & $2(7.7)$ & $5(19.2)$ & $4(8)$ & $8(16)$ & 0 & $1(16.7)$ \\
\hline$\cdot>10$ days & $18(16.4)$ & 0 & $2(7.7)$ & $3(6)$ & $2(4)$ & $2(66.7)$ & $3(50)$ \\
\hline \multicolumn{8}{|l|}{ Residential Status } \\
\hline • Rural & $48(43.6)$ & $2(7.7)$ & $6(23.1)$ & $9(18)$ & $11(22)$ & 0 & $1(16.7)$ \\
\hline - Urban & $62(56.4)$ & $7(26.9)$ & $11(42.3)$ & $17(34)$ & $13(26)$ & $3(100)$ & $5(83.3)$ \\
\hline \multicolumn{8}{|l|}{ Socioeconomic Status } \\
\hline - Lower Class & $69(62.7)$ & $4(15.4)$ & $9(34.6)$ & $9(18)$ & $13(26)$ & $3(100)$ & $6(100)$ \\
\hline - Middle Class & $40(36.4)$ & $5(19.2)$ & $8(30.8)$ & $16(32)$ & $11(22)$ & 0 & 0 \\
\hline - Higher Class & $1(0.9)$ & 0 & 0 & $1(2)$ & 0 & 0 & 0 \\
\hline \multicolumn{8}{|l|}{ Vancomycin use } \\
\hline - Yes & $14(12.7)$ & $2(7.7)$ & $3(11.5)$ & $4(8)$ & $1(2)$ & $1(33.3)$ & $3(50)$ \\
\hline - No & 96 (87.3) & $7(26.9)$ & $14(53.8)$ & $22(44)$ & $23(46)$ & $2(66.7)$ & $3(50)$ \\
\hline
\end{tabular}

All VRE isolates were from patients with lower socioeconomic class, while other classes were colonized with VSE only (Table 6). Socioeconomic status of patients showed significant association with respect to isolation of enterococci from perirectal area (Chi-square test: 19.163, $\mathrm{P}<0.05)$, but no association with nasal isolates was found (Chi-square test: $4.598, \mathrm{P}>0.05$ ). The patients on vancomycin treatment were colonized with 01/03 (33.3\%) nasal and 03/06 (50\%) perirectal VRE. There was significant relationship of vancomycin treatment with perirectal enterococcal isolation (Chi-square test: 10.881, $\mathrm{P}<0.05)$ while no significant association was present with nasal isolates (Chi-square test: 4.341, $\mathrm{P}>0.05)$.
Frequency of enterococci in rural and urban patients

There was high isolation of both E. faecalis and E. faecium from urban patients than the rural patients (Table 6). There were 08/09 (88.9\%) VRE from urban patients and 01/09 (9.1\%) from rural. In 29 nasal isolates, all the 03/03 VRE (02 E. faecalis and 01 E. faecium) were from urban patients. VSE from urban and rural were 18/ 26 (26.9\% E. faecalis and $42.3 \%$ E. faecium) and $08 / 26$ (7.7\% E. faecalis and $23.1 \%$ E. faecium) respectively. However, no statistically significant association of residential status with nasal isolates was present (Chi-square test: 5.569, $\mathrm{P}>0.05$ ).

From 56 perirectal isolates, VRE were 05/06 (83.3\%) from urban including $03 \mathrm{E}$. faecalis and $02 \mathrm{E}$. faecium 
and 01/06 (16.7\%) E. faecium from rural while VSE were $30 / 50$ (34\% E. faecalis and 22\% E. faecium) from urban and $20 / 50$ (18\% E. faecalis and 22\% E. faecium) from rural patients. Association was statistically not significant with perirectal isolates (Chi-square test: $4.249, \mathrm{P}>0.05$ ).

\section{Association between clinical diagnosis and enterococcal colonization}

The admitted patients with different disease conditions were categories into seven groups that were aspiration pneumonia, meningitis, pneumonia, renal failure, tetanus, tuberculosis and miscellaneous group. Diseases which appeared in more than five patients were given a separate group and diseases which were in less than five patients were grouped into "miscellaneous group". Patients presented with pneumonia and with miscellaneous diseases were more colonized with VRE and VSE. In nasal VSE, 20/26 (26.9\% E. faecalis and 50\% E. faecium) isolates were from pneumonia patients, while $01 / 26$ (3.9\% E. faecium) isolate was from a patient with meningitis and $05 / 26(7.7 \%$ E. faecalis and $11.5 \%$ E. faecium $)$ were from the miscellaneous group. There were 02/03 $\operatorname{VRE}$ (E. faecalis) from pneumonia and 01/03 VRE (E. faecium) was from a patient in miscellaneous group (Table 6). However, no significant association was found with nasal isolates (Chi-square test: 9.350, P > 0.05).

Similarly, in perirectal VSE, 29/50 (30\% E. faecalis and $28 \%$ E. faecium) were isolated from pneumonia patients followed by other leading group "miscellaneous group" which were having $16 / 50$ (14\% E. faecalis and $18 \% E$. faecium) enterococci. Remaining 04/50 isolates (6\% E. faecalis and $2 \%$ E. faecium) were from patients with meningitis. No significant association with perirectal isolates (Chi-square test: 22.958, P >0.05). There were 12 patients who were suffering with pneumonia harboring enterococci both in nasal and perirectal samples. There was no significant correlation with other parameters of clinical data.

\section{Discussion}

E. faecalis and E. faecium are potentially good focal species for microbiological surveillance study as they accounts for 80 to $90 \%$ of human enterococcal infections [17]. These two species were focused in the present study also because these are the common nosocomial agents and normal inhabitants of human intestinal tract, female genital tract, and less commonly in oral cavity [18-20]. E. faecalis is the most frequently occurring species of enterococci [21] than others but in the present study, results depict that the isolation rates of both species E. faecalis and E. faecium were almost equal. Isolation of VRE is highly significant both in causing infection in the individuals themselves and in transmission of vancomycin resistance to staphylococci. In the present study, isolation of VRE and colonization of VSE in nasal samples is alarming although the carriage rate of nasal and perirectal VRE is not much high. A study by Karimi et al. [22] 16.9\% VRE were isolated from stool samples of hospitalized children. This isolation rate is much higher as compared to the present study. Burger \& Muller [23] reported the carriage rate of glycopeptide resistant enterococci (GRE) from different body sites. They concluded that in 20 patients, the GRE isolation was most frequently from stool samples (95\%) whereas from other sites, including mouth, nose, throat, rectum and perineum recovery was low (25\%). However, VRE isolation rate is very low in the present study but as a whole, there is high perirectal carriage rate of enterococci, which is usual. The nasal carriage rate is comparatively high in the present study, although the main areas of colonization and isolation for enterococci are stool, rectum and perirectal area [24]. Only few patients were positive for both perirectal-VRE and nasal-VRE. VRE were low in frequency but comparatively high in nasal samples. The higher nasal VSE colonization may be due to poor hygiene of the patients.

Out of several different genes mediating vancomycin resistance, vanA and vanB resistance gene were targeted for identification as these gene clusters can be acquired and often transferable [25]. PCR analysis successfully identified E. faecium and E. faecalis along with nasal and perirectal VRE using $d d l$ and $v a n A$ and $v a n B$ primers respectively (Table 2) like study of Dutka-Malen et al. [26].

High antimicrobial resistance is a characteristic of the enterococci, although some species like E. faecium are intrinsically more resistant than others [27]. In the present study, both the nasal and perirectal E. faecium isolates were more resistant than E. faecalis isolates. None of the nasal and perirectal isolates including VRE were resistant to linezolid and quinupristin/dalfopristin, the drugs of choice for these isolates. All the isolates showed high resistance to gentamicin like a previous study [28]. In an Iranian study [29] MICs of vancomycin for VRE isolates were from 32 to $512 \mu \mathrm{g} / \mathrm{ml}$ with similar results in our study. MICs of tetracycline for nasal and perirectal enterococci were from 2 to $256 \mathrm{mg} / \mathrm{L}$ and 0.5 to $256 \mathrm{mg} / \mathrm{L}$ respectively, which correspond with another report [30]. Resistance to ciprofloxacin was higher than other reports [31].

The urban patients were more colonized with VRE than the rural patients. This difference might be due to the irrational use of antibiotics in urban community. In a study by Oberoi \& Aggarwal [32] high frequency of $E$. faecium in urban hospitalized patients was observed and that could be due to chronicity of cases or wider use of broad-spectrum antibiotics.

In a study by Berk \& Verghese [33] reported some Gram-positive cocci including enterococci have significance 
in nosocomial respiratory infection and there are chances of occurrence of enterococcal pneumonia in patients receiving broad-spectrum antibiotics [34,35]. In the present study, there is more isolation of enterococci both $E$. faecalis and E. faecium, from the patients of pneumonia. This might have some correlation with nosocomial respiratory infection. More prospective study in this regard is under consideration. Isolation rate of VRE was low and is not possible to correlate it with vancomycin use as has been reported that treatment with vancomycin is not a risk factor for VRE colonization and infection [36,37]. The present study was only a microbiological surveillance study and not a study of intervention to decrease colonization rate and analysis of nosocomial infections caused by VRE.

\section{Conclusion}

High nasal and perirectal colonization rate by E. faecalis and E. faecium in children in PICUs in particular $2.7 \%$ VRE and 23.6\% VSE nasal colonization is alarming as the anterior nares are not the common niche for these. Further studies are required to elaborate transfer of vancomycin-resistance genes in Staphylococcal nasal carriers co-colonized with VRE.

\section{Abbreviations \\ BAA: Bile aesculin agar; bp: Break point; E. faecalis: Enterococcus faecalis; $E$. faecium: Enterococcus faecium; GRE: Glycopeptide resistant enterococci; KFSA: KF streptococci agar; MHA: Mueller Hinton Agar; MICs: Minimum inhibitory concentrations; S. aureus: Staphylococcus aureus; SBA: Sheep blood agar; SPSS: Statistical package for social sciences; PICU: Paediatrics intensive care unit; VRE: Vancomycin-resistant enterococci; VSE: Vancomycin sensitive enterococci.}

\section{Competing interests}

The authors declare that they have no competing interests.

\section{Authors' contribution}

MAY and SI collected the clinical samples and performed the experiments; NA designed and supervised the whole study as well as edited the manuscript; MAY, AM and SAK analysed the clinical data and wrote the manuscript. All authors read and approved the final manuscript.

\section{Acknowledgment}

The authors thank RMC Allied Hospital, Rawalpindi, Pakistan, for providing data and allowing for collection of samples of patients.

\section{Author details}

${ }^{1}$ Department of Pharmaceutical Sciences, COMSATS Institute of Information Technology, Abbottabad 22060, Pakistan. ${ }^{2}$ Microbiology Research Laboratory, Department of Microbiology, Quaid-I-Azam University, Islamabad 45320, Pakistan. ${ }^{3}$ Department of Pathology, Rawalpindi Medical College, Rawalpindi 46300, Pakistan. ${ }^{4}$ Department of Microbiology, University of Health Sciences, Lahore 54600, Pakistan.

Received: 10 July 2012 Accepted: 15 March 2013

Published: 27 March 2013

\section{References}

1. Facklam RR, Sahm DF, Teixeira LM: Enterococcus. In Manual of clinical microbiology. 7th edition. Edited by Murray PR, Baron EJ, Pfaller MA, Tenover FC, Yoken RH. Washington, D.C: ASM Press; 1999:297-305.

2. Facklam RR, Sahm DF: Enterococcus. In Manual of clinical microbiology. 6th edition. Edited by Murray PR, Baron EJ, Pfaller MA, Tenover FC, Yoken RH. Washington, DC: ASM Press; 1995:308-314.
3. Moellering RC: Vancomycin-resistant enterococci. Clin Infect Dis 1998, 26:1196-1199.

4. Spera RV, Farber BF: Multiply-resistant Enterococcus-faecium - the nosocomial pathogen of the 1990s. JAMA 1992, 268:2563-2564.

5. Emori TG, Gaynes RP: An overview of nosocomial infections, including the role of the microbiology laboratory. Clin Microbiol Rev 1993, 6:428-442.

6. National Nosocomial Infections Surveillance System: National Nosocomial Infections Surveillance (NNIS) report, data summary from October 1986April 1997, issued May 1997. A report from the NNIS System. American Journal of Infection Control 1997, 25:477-487.

7. Chenoweth CE, Schaberg DR: Enerococcus species. In Hospital epidemiology and infection control. Edited by Mayhall CG. Baltimore: Williams \& Wilkins; 1996:334-345

8. Noble WC, Virani Z, Cree RG: Co-transfer of vancomycin and other resistance genes from Enterococcus faecalis NCTC 12201 to Staphylococcus aureus. FEMS Microbiol Lett 1992, 72:195-198.

9. Showsh SA, De Boever EH, Clewell DB: Vancomycin resistance plasmid in Enterococcus faecalis that encodes sensitivity to a sex pheromone also produced by Staphylococcus aureus. Antimicrob Agents Chemother 2001, 45:2177-2178.

10. Tiwari HK, Sen MR: Emergence of vancomycin resistant Staphylococcus aureus (VRSA) from a tertiary care hospital from northern part of India. BMC Infect Dis 2006, 6:156.

11. Frank DN, Feazel LM, Bessesen MT, Price CS, Janoff EN, Pace NR: The human nasal microbiota and Staphylococcus aureus carriage. PLoS One 2010, 5:15.

12. Kariyama R, Mitsuhata R, Chow JW, Clewell DB, Kumon H: Simple and reliable multiplex PCR assay for surveillance isolates of vancomycinresistant enterococci. J Clin Microbiol 2000, 38:3092-3095.

13. Louie L, Goodfellow J, Mathieu P, Glatt A, Louie M, Simor AE: Rapid detection of methicillin-resistant staphylococci from blood culture bottles by using a multiplex PCR assay. J Clin Microbiol 2002, 40:2786-2790

14. Mulder RH, Farnham SM, Grinius B: Evaluating antimicrobial susceptibility test systems. In Clinical microbiology procedures handbook. Edited by Isenberg H. Washington DC: ASM Press; 1995:1-14.

15. Clinical and Laboratory Standards Institute: Methods for Dilution Antimicrobial Susceptibility Tests for Bacteria that Grow Aerobically: Approved Standard. 8th edition. Wayne, Pennsylvania, USA: Clinical and Laboratory Standards Institute; 2009.

16. Andrews JM, BSAC Working Party on Susceptibility Testing: BSAC standardized disc susceptibility testing method (version 8). J Antimicrob Chemother 2009, 64:454-489.

17. Rathnayake IU, Hargreaves M, Huygens F: Genotyping of Enterococcus faecalis and Enterococcus faecium isolates by use of a set of eight single nucleotide polymorphisms. J Clin Microbiol 2011, 49:367-372.

18. Nannin EC, Murray BE: Enterococcus spp. In Principles and practice of clinical bacteriology. 2nd edition. Edited by Gillespie SH, Hawkey PM. West Sussex, UK: John Wiley \& Sons; 2006:59-71.

19. Teixeira LM, Carvalho MDGS, Facklam RR: Enterococcus. In Manual of clinical microbiology. 9th edition. Edited by Murray PR. Washington D.C: ASM Press; 2007:430-442.

20. Sweet RL, Gibbs RS: Infectious diseases of the female genital tract. 5th edition. Philadelphia, PA: Lippincott Williams \& Williams; 2009:480.

21. Harwood VJ, Delahoya NC, Ulrich RM, Kramer MF, Whitlock JE, Garey JR, Lim DV: Molecular confirmation of Enterococcus faecalis and E. faecium from clinical, faecal and environmental sources. Letters in applied microbiology 2004, 38:476-482.

22. Karimi A, Navidinia M, Tabatabaii SR, Fallah F, Malekan M, Jahromy H, Ahsani $\mathrm{RR}$, Shiva F: The prevalence of vancomycin resistance genes in enterococci isolated from the stool of hospitalized patients in Mofid children hospital. Gene Therapy And Molecular Biology 2009, 13:294-300.

23. Burger $\mathrm{H}$, Muller HE: Rhodococcus isolated from a gluteal abscess. Infection 1982, 10:343-346.

24. Weinstein JW, Tallapragada S, Farrel P, Dembry LM: Comparison of rectal and perirectal swabs for detection of colonization with vancomycinresistant enterococci. J Clin Microbiol 2002, 40:210-212.

25. Murray BE: Diversity among multidrug-resistant enterococci. Emerg Infect Dis 1998, 4:37-47.

26. Dutka-Malen S, Evers S, Courvalin P: Detection of glycopeptide resistance genotypes and identification to the species level of clinically relevant enterococci by PCR. J Clin Microbiol 1995, 33:1434 
27. Gold HS: Vancomycin-resistant enterococci: mechanisms and clinical observations. Clin Infect Dis 2001, 33:210-219.

28. Caballero-Granado FJ, Cisneros JM, Luque R, Torres-Tortosa M, Gamboa F, Diez F, Villanueva JL, Perez-Cano R, Pasquau J, Merino D, Menchero A, Mora D, Lopez-Ruz MA, Vergara A: Comparative study of bacteremias caused by Enterococcus spp. with and without high-level resistance to gentamicin. Journal of Clinical Microbiology 1998, 36:520-525.

29. Aleyasin A, Mobarez AM, Sadeghizadeh M, Doust RH, Khoramabadi N: Resistance to vancomycin in Enterococcus faecium and faecalis clinical isolates. Pakistan Journal of Medical Sciences 2007, 23:4-7.

30. Kowalska-Krochmal B, Dworniczek E, Dolna I, Seniuk A, Bania J, Walecka E, Wrzyszcz E: Antibiotic susceptibility levels of clinical Enterococcus spp. Strains, including those resistant to glycopeptides and high concentrations of aminoglycosides. Advances in Clinical and Experimental Medicine 2010, 19:155-162.

31. Cotter G, Adley CC: Ciprofloxacin susceptibility testing of enterococcal urinary isolates in accordance with BSAC guidelines. J Antimicrob Chemother 2001, 48:324-325.

32. Oberoi L, Aggarwal A: Multidrug resistant enterococci in a rural tertiary care hospital-a cause of concern. JK Science: Journal of Medical Education \& 2010, 12:157-158.

33. Berk SL, Verghese A: Emerging pathogens in nosocomial pneumonia. Eur J Clin Microbiol Infect Dis 1989, 8:11-14.

34. Grupper M, Kravtsov A, Potasman I: Enterococcal-associated lower respiratory tract infections: a case report and literature review. Infection 2009, 37:60-64.

35. Berk SL, Verghese A, Holtsclaw SA, Smith JK: Enterococcal pneumonia. Occurrence in patients receiving broad-spectrum antibiotic regimens and enteral feeding. The American journal of medicine 1983, 74:153-154.

36. Carmeli Y, Eliopoulos GM, Samore MH: Antecedent treatment with different antibiotic agents as a risk factor for vancomycin-resistant Enterococcus. Emerg Infect Dis 2002, 8:802-807.

37. Nahum E, Samra Z, Ben-Ari J, Dagan O, Schonfeld T, Ashkenazi S: Fecal Emergence of Vancomycin-Resistant Enterococci after Prophylactic Intravenous Vancomycin. The Internet Journal of Infectious Diseases 2002, 2:19.

doi:10.1186/1471-2334-13-156

Cite this article as: Yameen et al:: Nasal and perirectal colonization of vancomycin sensitive and resistant enterococci in patients of paediatrics ICU (PICU) of tertiary health care facilities. BMC Infectious Diseases 2013 13:156.

\section{Submit your next manuscript to BioMed Central and take full advantage of:}

- Convenient online submission

- Thorough peer review

- No space constraints or color figure charges

- Immediate publication on acceptance

- Inclusion in PubMed, CAS, Scopus and Google Scholar

- Research which is freely available for redistribution 